\title{
Occurrence and spatial distribution of phthalate esters in sediments of the Bohai and Yellow seas
}

\author{
Lijie Mi ${ }^{\mathrm{a}}$, Zhiyong Xie ${ }^{\mathrm{b}, *}$, Zhen Zhao $^{\mathrm{c}}$, Mingyu Zhong ${ }^{\mathrm{a}}$, Wenying Mi ${ }^{\mathrm{d}}$, Ralf Ebinghaus ${ }^{\mathrm{b}}$, Jianhui Tang ${ }^{\mathrm{a}}$ \\ ${ }^{a}$ Key Laboratory of Coastal Environmental Processes and Ecological Remediation, Yantai Institute of Coastal Zone Research, CAS, Yantai 264003, China \\ ${ }^{\mathrm{b}}$ Helmholtz-Zentrum Geesthacht, Centre for Materials and Coastal Research, Institute of Coastal Research, Geesthacht 21502, Germany \\ ${ }^{\text {c } M O E}$ Key Laboratory of Pollution Processes and Environment Criteria, College of Environmental Science and Engineering, Nankai University, Tianjin 300350, China \\ ${ }^{\mathrm{d}}$ MINJIE Institute of Environmental Science and Health Research, Geesthacht 21502, Germany
}

\section{H I G H L I G H T S}

- Phthalate esters are ubiquitous contamination in the Chinese Marginal seas.

- DEHP, DiBP and DnBP are more abundant in marine sediment.

- Total organic carbon content is an important factor effect the accumulation of PEs in the sediment.

- The inventories of the $\sum$ GPAEs were 20.73 tons in the Bohai Sea and 65.87 tons in the Yellow Sea.

\section{G R A P H I C A L A B S T R A C T}
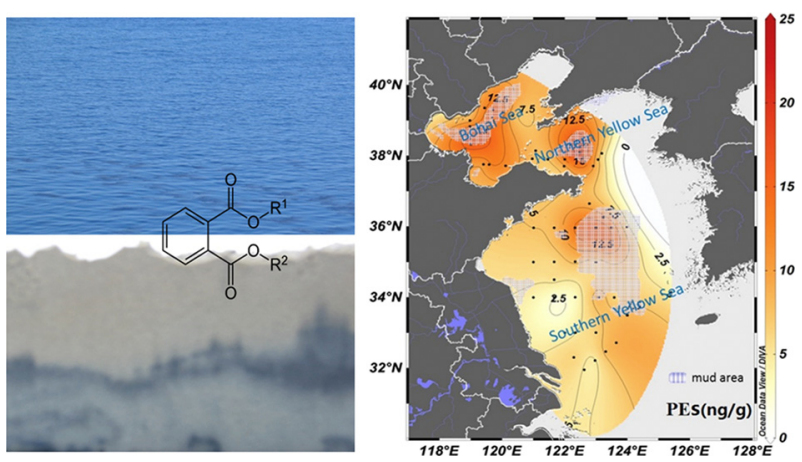

\section{A B S T R A C T}

Phthalate esters (PEs) are a class of synthetic chemicals that have been widely used as plasticizers in industrial products and households. The occurrence of PEs in the marine environment has been a concern for many years because of their adverse impacts on marine organisms and human health. In this study, six major PEs, i.e. diethyl phthalate (DEP), di-isobutyl phthalate (DiBP), di-n-butyl phthalate (DnBP), benzylbutyl phthalate (BBP), dicyclohexyl phthalate (DCHP) and di-(2-ethylhexyl) phthalate (DEHP), were analyzed in sediment samples collected in the Bohai and Yellow seas. The sum concentrations of the six PEs ranged from 1.4 to $24.6 \mathrm{ng} / \mathrm{g}$ and the average was $9.1 \mathrm{ng} / \mathrm{g}$. The highest concentrations of PEs in the sediment samples were those of DEHP with a median concentration of $3.77 \mathrm{ng} / \mathrm{g}$, followed by DiBP (median, $1.60 \mathrm{ng} / \mathrm{g})$, DnBP (0.91 ng/g), DEP (0.32 ng/g), BBP (0.03 ng/g) and DCHP (0.01 ng/g). Generally, concentrations of PEs in the Bohai Sea are higher than those in the Yellow Sea. The varying spatial distributions of the individual PEs can be the result of discharge sources, regional ocean circulation patterns, and mud areas in the Bohai and Yellow seas. Significant positive correlations were found between total organic carbon content and the concentrations of DiBP, DnBP, and DEHP. It is estimated that the inventories of the $\sum 6$ PEs were 20.73 tons in the Bohai Sea and 65.87 tons in the Yellow Sea. Both riverine discharge and atmospheric deposition are major input sources for the PE sedimentation, while massive plastic litter and microplastics sinking to the ocean floor can directly release PEs into sediment. This study provides an appropriate data set for the assessment of the risk of PEs to the marine ecosystem.

(c) 2018 Elsevier B.V. All rights reserved.

\footnotetext{
* Corresponding author.

E-mail address: zhiyong.xie@hzg.de (Z. Xie).
} 


\section{Introduction}

Phthalate esters (PEs) are a class of synthetic chemicals and have been widely used as plasticizers in industrial products and households, such as in children's toys, food packaging, lubricants, adhesives, paints, building materials, pharmaceuticals, and personal care products (Staples et al., 1997b). Global PE production exceeds 8.0 million tons annually (Paluselli et al., 2018a). As PEs are not chemically bonded to plastic polymers, they are easily released into the environment during the processes of manufacturing and application via evaporation and leaching from domestic and industrial effluents (Fujii et al., 2003; Kastner et al., 2012; Liu et al., 2013). Recently, PEs have been listed as priority control pollutants in the European Union (EU), by the Environmental Protection Agency (EPA) in the United States, and by the Chinese State Environmental Protection Administration. Moreover, PEs have shown developmental toxicity and estrogenic endocrine disrupting activity in biological toxicity tests (Chen et al., 2011; Staples et al., 1997a; Weir et al., 2014; Xu et al., 2013). Extensively application of PE-containing products in industry and households has leaded that PEs are ubiquitous in various environments (Klamer et al., 2005; Peijnenburg and Struijs, 2006; Fernandez et al., 2007; Xie et al., 2007). The aquatic transport is thought to be among the important transport routes for PEs presence in the marine environment (Ajdari et al., 2018; Paluselli et al., 2018b; Xie et al., 2005; Paluselli et al., 2018a). Once PEs reach the marine environment, they distribute in the water, particulates, and sediments. It has been proven that sediments are important sinks and sources for PE distribution and bioaccumulation in the marine environment (Chen et al., 2013; Huang et al., 2008; Peijnenburg and Struijs, 2006; Wang et al., 2014).

The Bohai and Yellow seas have a combined total area exceeding $450,000 \mathrm{~km}^{2}$, with an average water depth of $18 \mathrm{~m}$ for the Bohai Sea and $50 \mathrm{~m}$ for the Yellow Sea (Chen, 2009). They are semi-closed shallow shelf seas, affected by the dynamic processes of tides, waves, and regional oceanic currents. Hundreds of rivers in China as well as the Korean Peninsula discharge industrial and domestic effluents into this region. This leads to high concentrations of total suspended sediment matter. The annual sediment load from the Yellow River to the Bohai Sea is 1.08 billion tons annually. Of this, approximately 40 to $100 \mathrm{mt} /$ year sediment are transported into the Yellow Sea through the Bohai Strait. Moreover, the Yellow Sea receives high suspended matter discharge from the Yangtze River $\left(5 \times 10^{8}\right.$ tons/year), Huaihe $(\sim 1$ $\times 10^{7}$ tons/year) and Korean rivers ( $<1 \times 10^{7}$ tons/year) as well (Qiao et al., 2017; Wang et al., 2016; Yang et al., 2003). During the last few decades, the Bohai and Yellow seas have attracted increasing concern because of their natural variations caused by global climate change and land applications in China and Korea (Liu et al., 2004). Particularly, elevated environmental pressures from manufactured chemicals have threatened the biological productivities of their marine ecosystems (Meng et al., 2017). Recently, many organic contaminants have been found in the sediment and seawater of the Bohai and Yellow seas $\mathrm{Hu}$ et al., 2009; Li et al., 2018; Zhao et al., 2013; Zhong et al., 2015), which indicated the synthetic organic chemicals can be an emerging concern for the marine ecosystem of the Chinese marginal seas.

Several studies have investigated PEs in large rivers and estuaries along the Chinese coast, while studies in the open sea are still limited (Sha et al., 2007; Wang et al., 2014; Sun et al., 2013; Zhang et al., 2017, 2018b). Sha et al. (2007) reported PEs in sediments of the Yellow River ranging from 30.5 to $85.2 \mathrm{mg} / \mathrm{kg}$. Zhang et al. (2018b) recently reported 16 PEs in the sediments from Bohai and Yellow seas (1.24 to $15.8 \mathrm{mg} / \mathrm{kg}$ ), which are comparable to those measured in the sediment samples of Yangtze River Estuary and its adjacent area (0.48-29.94 mg/kg) (Zhang et al., 2018b), but much higher than those reported in 2017 (0.00079-0.0348 mg/kg) (Zhang et al., 2017). Furthermore, these studies demonstrated that PE concentrations in sediment are several orders of magnitude higher than other emerging organic contaminants, e.g. polybrominated diphenyl ethers (PBDE) (Pan et al.,
2010), polyfluorinated alkyl substances (PFAS) (Gao et al., 2014), and organophosphate esters (OPE) (Zhong et al., 2018). Obviously, more research is necessary to provide reliable data for carrying out risk assessment of PEs in the Chinese coast.

The objective of this work was to conduct a systematic survey to determine the spatial distribution and pattern of six major PEs in sediments in the Bohai and Yellow seas. The chemical and physical properties of the selected PEs are listed in Table S1. The impact of total organic carbons (TOCs) on the accumulation of PEs in the sediments was also investigated. Furthermore, the PE inventories in sediment were estimated for the Bohai and Yellow seas.

\section{Materials and methods}

\subsection{Sample collection}

Marine sediment samples were collected onboard the research vessel Dongfanghong 2 during the Chinese Natural Science Foundation Expedition of 2009. The sampling stations approximately followed westeast transects and covered the Southern Yellow Sea, Northern Yellow Sea and Bohai Sea. Briefly, 54 surface sediment samples (from the top $10 \mathrm{~cm}$ ) were collected using a stainless-steel box corer, scooped using a pre-cleaned stainless-steel scoop, and placed into aluminum containers that had been baked at $450{ }^{\circ} \mathrm{C}$ for $8 \mathrm{~h}$ and solvent-rinsed prior to use. All samples were stored at $-20{ }^{\circ} \mathrm{C}$ until further treatment. Sediments were freeze-dried, grinded, and then sieved using 100-mesh. The homogenized sediment was packed into a $50-\mathrm{mL}$ brown vial and stored at $-20{ }^{\circ} \mathrm{C}$ for analysis.

\subsection{Extraction, clean-up, and analysis}

Ten grams of sediment were mixed with $10 \mathrm{~g}$ of anhydrous $\mathrm{Na}_{2} \mathrm{SO}_{4}$ and then packed into a $100-\mathrm{mL}$ Soxhlet extractor and spiked with 40 $\mu \mathrm{L}$ of deuterated surrogate standards of $125 \mathrm{pg} / \mu \mathrm{L}$ of d4-TEP, d4-TnBP, and d4-DEHP extracted with DCM for $16 \mathrm{~h}$ at a flow rate of $5 \mathrm{~mL} / \mathrm{min}$. Ten pieces of cupper beads were added into the extract to remove elemental sulfur. Extracts were evaporated to 1-2 mL using hexane as a keeper and further cleaned on a silica column ( $2.5 \mathrm{~g}, 10 \%$ water deactivated) topped with $3 \mathrm{~g}$ of anhydrous granulated sodium sulfate. The extract was purified by eluting with $20 \mathrm{~mL}$ of $n$-hexane (fraction 1 ) and $20 \mathrm{~mL}$ of DCM/acetone $\left(1,1_{\mathrm{V} / \mathrm{v}}\right)$ (fraction 2 ). Fraction 2 was concentrated to $200 \mu \mathrm{L}$ by roti-evaporation and nitrogen blower. Ten microliters of $50 \mathrm{pg}{ }^{13} \mathrm{C}_{6}-\mathrm{PCB} 208$ (Cambridge Isotope Laboratories) were added to the sample as an injection standard.

The samples were analyzed using an Agilent $6890 \mathrm{~N}$ gas chromatographer (GC) coupled to an Agilent 5975 mass spectrometer (MS) (Agilent Technologies, Avondale, PA, USA), in electron impact mode (EI), equipped with an HP-5MS column (30 $\mathrm{m} \times 0.25 \mathrm{~mm}$ i.d. $\times 0.25$ $\mu \mathrm{m}$ film thickness, J\&W Scientific). The injector was operated in the pulsed-splitless mode with an inlet temperature program as follows, $60{ }^{\circ} \mathrm{C}$ for $0.1 \mathrm{~min}$ then $300{ }^{\circ} \mathrm{C} / \mathrm{min}$ until $280{ }^{\circ} \mathrm{C}$ and then held for $10 \mathrm{~min}$. The GC oven temperature program was as follows, initially 60 ${ }^{\circ} \mathrm{C}$ for $2 \mathrm{~min}$, then $30{ }^{\circ} \mathrm{C} / \mathrm{min}$ until $130{ }^{\circ} \mathrm{C}$, followed by $2{ }^{\circ} \mathrm{C} / \mathrm{min}$ until $240{ }^{\circ} \mathrm{C}$, then $30^{\circ} \mathrm{C} / \mathrm{min}$ until $300^{\circ} \mathrm{C}$ and finally held for $4 \mathrm{~min}$. The temperature of the MS transfer line, MS source, and quadrupole were 280, 230 , and $150{ }^{\circ} \mathrm{C}$, respectively.

\subsection{Quality assurance and quality control}

Four method blanks were used in this work. Mean blank values of the PEs were $0.38,0.37,0.32,0.066,0.005$, and $2.1 \mathrm{ng} / \mathrm{g}$ for diethyl phthalate (DEP), di-isobutyl phthalate (DiBP), di- $n$-butyl phthalate (DnBP), benzylbutyl phthalate (BBP), dicyclohexyl phthalate (DCHP) and di-(2-ethylhexyl) phthalate (DEHP), respectively. Method detection limits (MDLs) were defined as three times the standard deviation $(\sigma)$ derived from the method blanks. The MDLs were 0.83, 0.12, 0.19, 
0.037, 0.005, and $1.32 \mathrm{ng} / \mathrm{g}$ for DEP, DiBP, DnBP, BBP, DCHP, and DEHP, respectively. Ten microliters of PE standard mixture $(10 \mathrm{ng} / \mu \mathrm{L}$ in acetone) were spiked in three parallel sediment samples and extracted simultaneously with other sediment samples. The recoveries were 118 $\pm 23,77 \pm 4,81 \pm 3,103 \pm 15,80 \pm 6$ and $81 \pm 23 \%$ for DEP, DiBP, DnBP, BBP, DCHP, and DEHP, respectively. Extraction efficiency was further checked with twice extraction for three sediment samples, which showed that the proportion of 6 PEs in first extraction ranged from 76 to $98 \%$. Quantification was performed using the internal calibration method based on a seven-point calibration curve for individual PEs. The coefficients of correlation $\left(R^{2}\right)$ were $0.9998,0.9985,0.9989$, 0.9925, 0.9942, and 0.9974 for DEP, DiBP, DnBP, BBP, DCHP, and DEHP, respectively. If the PE concentrations in the samples were $\leq \mathrm{MDLs}$, they were reported as not detected (nd). Concentrations of the sediments were corrected with surrogate recoveries and subtracted with average blanks.

\subsection{Total organic carbon (TOC) and total inorganic carbon (TIC) analysis}

The total organic carbon (TOC) and total inorganic carbon (TIC) of the freeze-dried sediments were determined using a LECO ${ }^{\circ}$ RC612 multiphase carbon and hydrogen/moisture analyzer as described in the literature (Chen et al., 2016). The TOC and TIC of the sediments in this study range from $0.03 \%$ to $0.90 \%$ (average, $0.37 \pm 0.23 \%$ ) and $0.11 \%$ to $1.67 \%$ (average, $0.61 \pm 0.30 \%$ ), respectively. There are no significant differences in the TOC and TIC among the Bohai, Northern Yellow, and Southern Yellow seas. The details of the TOC and TIC measurements are shown in the supporting information (Table S1).

\subsection{Data analysis}

The data were subjected to statistical analysis using Microsoft Excel 2016 and Origin 2017G (OriginLab Corporation, Northampton, MA) software. Sediment sampling stations and oceanographic visualization of the Bohai and Yellow seas were plotted using Ocean Data View 4 software (Schlitzer, 2018). Spearman analysis for the correlation between different PE compounds was conducted by IBM SPSS 20.

\section{Results and discussion}

\subsection{Occurrences and levels}

The concentrations of the six PEs (DEP, DiBP, DnBP, BBP, DCHP, and DEHP) in the sediments from the Bohai and Yellow seas are summarized in Table 1 (see Table S2 for details). PEs were detected in all of the sediment samples analyzed, indicating that they are ubiquitous contaminants in the studied marine environment. The sum of the six selected PE concentrations ( $\sum_{6} \mathrm{PE}$ ) obviously varied, ranging from 1.37 to $24.6 \mathrm{ng} / \mathrm{g}$ dry weight (dw), with an average of $9.1 \mathrm{ng} / \mathrm{g}$ and a median of $8.1 \mathrm{ng} / \mathrm{g}$. Among the six PEs, DEP, DiBP, DnBP, and DEHP were detected in $>90 \%$ of the sediment samples, while BBP and DCHP were detectable in 66 and 26\% of the sediment samples. The highest PE concentrations in the sediment samples were those of DEHP with a median concentration of $3.77 \mathrm{ng} / \mathrm{g}$, followed by $\mathrm{DiBP}(1.60 \mathrm{ng} / \mathrm{g})$, DnBP (0.91 ng/g), DEP (0.32 ng/g), BBP (0.03 ng/g) and DCHP (0.01 ng/g).

\subsection{Spatial distributions}

The spatial distribution of $\sum 6 \mathrm{PEs}$ in the surface sediments of the Bohai and Yellow seas is shown in Fig. 1. $\sum$ 6PEs observed in the Bohai Sea (mean, $11.8 \mathrm{ng} / \mathrm{g}$, median, $11.8 \mathrm{ng} / \mathrm{g}$ ) was slightly higher than those presented in the Northern Yellow Sea (mean, $10.8 \mathrm{ng} / \mathrm{g}$, median, $8.9 \mathrm{ng} / \mathrm{g}$ ) and Southern Yellow Sea (mean, $7.4 \mathrm{ng} / \mathrm{g}$, median, $7.2 \mathrm{ng} / \mathrm{g}$ ), suggesting PE accumulation discharged via riverine systems. Interestingly, the highest $\sum 6$ PEs concentration (24.6 ng/g-dw) was found at site B44, which is in the Northern Yellow Sea near the Bohai Strait. According to the study for the sedimentation rate in the Bohai and Yellow seas (Qiao et al., 2017), sediments from the Bohai coast can be transported along the Shandong Peninsula and form a mud zone in the Northern Yellow Sea. Consequently, the sediments originated from the highly contaminated Laizhou Bay may cause the high PE level at B44. The lowest $\sum 6$ PE concentration (1.4 ng/g-dw) was found at site H23 in the Southern Yellow Sea, which is located in a clayed sand area (Shi, 2014; Qiao et al., 2017). The hydrodynamics and currents of the east China seas are very complex and influenced by the monsoon, fluvial runoff, Kuroshio Current, tide-induced residual currents, sea contours and topography (Su and Yuan, 2005). There are no obvious spatial PE trends along the west-east sampling transects, which could contribute to the complex dynamic conditions of the marginal seas.

The spatial distributions of individual PEs are shown in Fig. 2. DEHP obviously showed a decreasing trend from the Bohai Sea (median, $8.3 \mathrm{ng} / \mathrm{g}$ ) to the Northern Yellow Sea $(3.5 \mathrm{ng} / \mathrm{g}$ ) and the Southern Yellow Sea (median, $2.0 \mathrm{ng} / \mathrm{g}$ ). The DiBP and DnBP concentrations in the Northern Yellow Sea (median, 2.1, $1.0 \mathrm{ng} / \mathrm{g}$ ) are slightly higher than those in the Bohai Sea (median, 1.7, $1.0 \mathrm{ng} / \mathrm{g}$ ) and the Southern Yellow Sea (median, $1.52,0.8 \mathrm{ng} / \mathrm{g}$ ). However, a high level of DEP occurs in the Southern Yellow Sea (median, $0.59 \mathrm{ng} / \mathrm{g}$ ) and which is approximately 2 times higher than that of the Bohai Sea (median, $0.33 \mathrm{ng} / \mathrm{g}$ ) and $>10$ times higher than that of the Northern Yellow Sea (median, $0.04 \mathrm{ng} / \mathrm{g}$ ). The varying spatial distributions of the individual PEs were related to the PE discharge sources, regional oceanic circulation patterns, and mud areas in the Bohai and Yellow seas. Generally, organic contaminants can be transported into the marine environment from a riverine catchment as well as from atmospheric dry and wet deposition (Jurado et al., 2004; Xie et al., 2005). There are $>40$ rivers flowing into the Bohai and Yellow seas, which discharge $\sim 782.2 \times 10^{6}$ ton/year of sediment into the Bohai Sea and $13.0 \times 10^{6}$ ton/year into the Yellow Sea (Qiao et al., 2017). The log octanol-water partition coefficient (logKow) has been considered a key parameter for the measurement of organic pollutants in environmental fate modeling as it is correlated with water solubility and bioaccumulation (Schwarzenbach et al., 2002). DEHP, DCHP, and BBP have $\log K_{\text {ow }}$ values of 7.50, 6.20, and 4.59 (Staples et al., 1997b), respectively, suggesting they likely partition to particular matter and settle during the sedimentation process. Therefore, DEHP and DCHP may accumulate in coastal areas and transport with fine particles to remote

Table 1

Concentrations of PEs (ng/g) in sediment of Bohai, northern and southern Yellow seas.

\begin{tabular}{|c|c|c|c|c|c|c|c|c|c|c|c|c|}
\hline \multirow[t]{2}{*}{ PE (ng/g) } & \multicolumn{4}{|c|}{ Bohai Sea } & \multicolumn{4}{|c|}{ Northern Yellow Sea } & \multicolumn{4}{|c|}{ Southern Yellow Sea } \\
\hline & Mean & Median & Min & Max & Mean & Median & Min & Max & Mean & Median & Min & Max \\
\hline DEP & 0.40 & 0.33 & 0.08 & 1.12 & 0.06 & 0.04 & n.d. & 0.29 & 0.80 & 0.59 & n.d. & 2.50 \\
\hline DiBP & 1.66 & 1.67 & 0.77 & 2.58 & 2.10 & 2.13 & 0.72 & 4.08 & 1.99 & 1.52 & 0.22 & 6.40 \\
\hline DnBP & 1.04 & 1.00 & 0.35 & 2.24 & 2.72 & 1.05 & 0.55 & 6.79 & 1.07 & 0.83 & n.d & 3.85 \\
\hline BBP & 0.07 & 0.03 & n.d & 0.43 & 0.07 & 0.06 & n.d. & 0.18 & 0.10 & 0.03 & n.d. & 1.55 \\
\hline DCHP & 0.01 & 0.01 & n.d & 0.03 & 0.01 & 0.01 & n.d. & 0.05 & 0.01 & n.d. & n.d. & 0.05 \\
\hline DEHP & 8.63 & 8.34 & 0.04 & 15.9 & 5.83 & 3.53 & 1.93 & 15.6 & 3.43 & n.d. & n.d. & 10.4 \\
\hline$\sum 6 P E$ & 11.8 & 11.8 & 1.83 & 18.5 & 10.8 & 8.87 & 4.59 & 24.6 & 7.40 & 7.18 & 1.4 & 16.7 \\
\hline
\end{tabular}




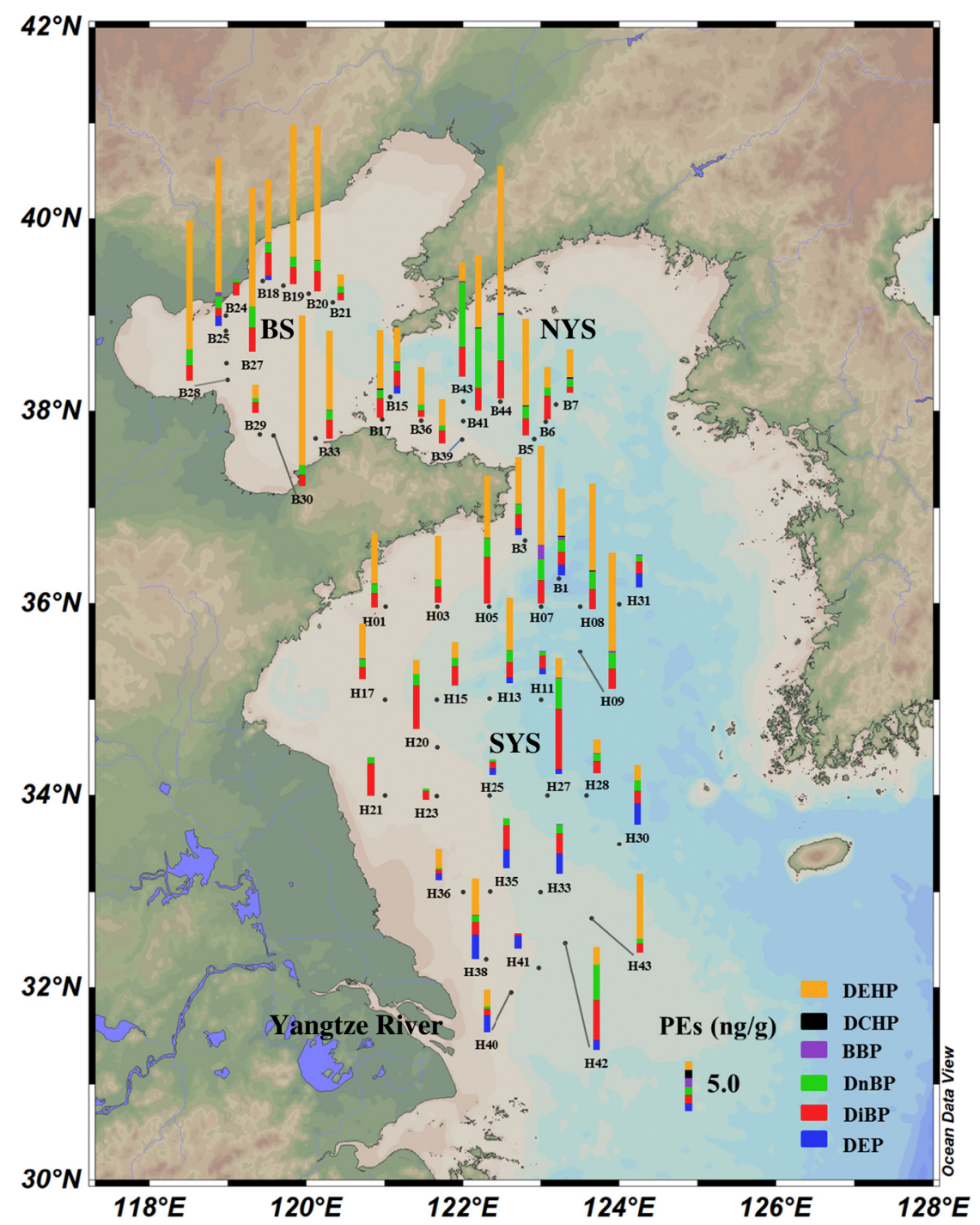

Fig. 1. Spatial distribution of $\sum 6 \mathrm{PEs}(\mathrm{ng} / \mathrm{g})$ in the surface sediment of the Bohai, Northern and Sothern Yellow seas (BS, NYS and SYS).

areas, while DEP ( $\log K_{\mathrm{OW}}, 2.38$ ) (Staples et al., 1997b) is very soluble in water and can be transported with the water mass from the Bohai Sea to the Yellow Sea. Moreover, the northward water mass from the Yangtze estuary may also be responsible for the high PE concentrations occurring in the Southern Yellow Sea (Zhang et al., 2018b). Nevertheless, the distribution pattern of the PE components illustrates obvious fractionation of different PEs during transportation from emission sources to remote areas.

\subsection{Comparison to previous studies}

Analysis of PEs in marine sediments is rare, though there are some data to describe the pollution status of PEs in the sediments of rivers and estuaries as shown in Table 2. In these previous studies, DnBP and DEHP were the most predominant compounds. DnBP and DEHP concentrations in sediments of the Bohai and Yellow seas were usually 1-3 orders of magnitude lower than those detected in riverine, estuarine and coastal sediments (Adeniyi et al., 2011; Du et al., 2013; Sha et al., 2007; Stewart et al., 2014; Stoppa et al., 2017; Zhang et al., 2018b; Fatoki et al., 2009; Li et al., 2017; Hassanzadeh et al., 2014; Yang et al., 2016). Zhang et al. reported DEP, DiBP, DnBP, and DEHP in the Yangtze River estuary, which showed a comparable level in 2017 and a relatively high level in 2018 in comparison to values in this study (Zhang et al., 2017; Zhang et al., 2018b). BBP concentrations in sediment of the Bohai and Yellow seas were comparable to those in the Maowei Sea and lower than those in the coastal zone of Qingdao, Changjiang River, and Kaohsiung Harbor (Chen et al., 2013, Zhang et al., 2016, Zhang et al., 2018b, Liao et al., 2015). DCHP concentrations measured in the Chaohu Lake and Qiantang River are comparable to those in this work (Kang et al., 2016; Sun et al., 2013), while the DCHP reported in the Pearl River Delta and coastal zone of New Zealand are 2-3 orders of magnitude higher than that in this study (Stewart et al., 2014; Zeng et al., 2008). The PE concentrations in sediments of the Bohai and Yellow seas are 1-2 orders of magnitude lower than those measured in Laizhou and Quanzhou bays and the Haihe and Yellow rivers, suggested riverine catchment is a significant pathway for the transport of DnBP and DEHPs into the Bohai and Yellow seas (Chi, 2009; Sha et al., 2007; Xiao et al., 2010; Zhuang et al., 2011).

\subsection{Correlation between PEs and total organic carbon}

The mean value of TOC in the Bohai, North Yellow, and South Yellow seas was $0.33 \%, 0.41 \%$, and $0.37 \%$, respectively. The TOC contents were obviously higher in the clay regions, which is consistent with the PE horizontal distribution (Fig. 3). Significant positive correlations exist between concentrations of $\Sigma$ 6PEs and TOC $(r=0.62, p<0.001)$ in the Bohai and Yellow seas (Fig. S1). The TIC ranged from $0.11 \%$ to $1.67 \%$ with a mean of $0.61 \pm 0.30 \%$. The linear regression analysis showed 

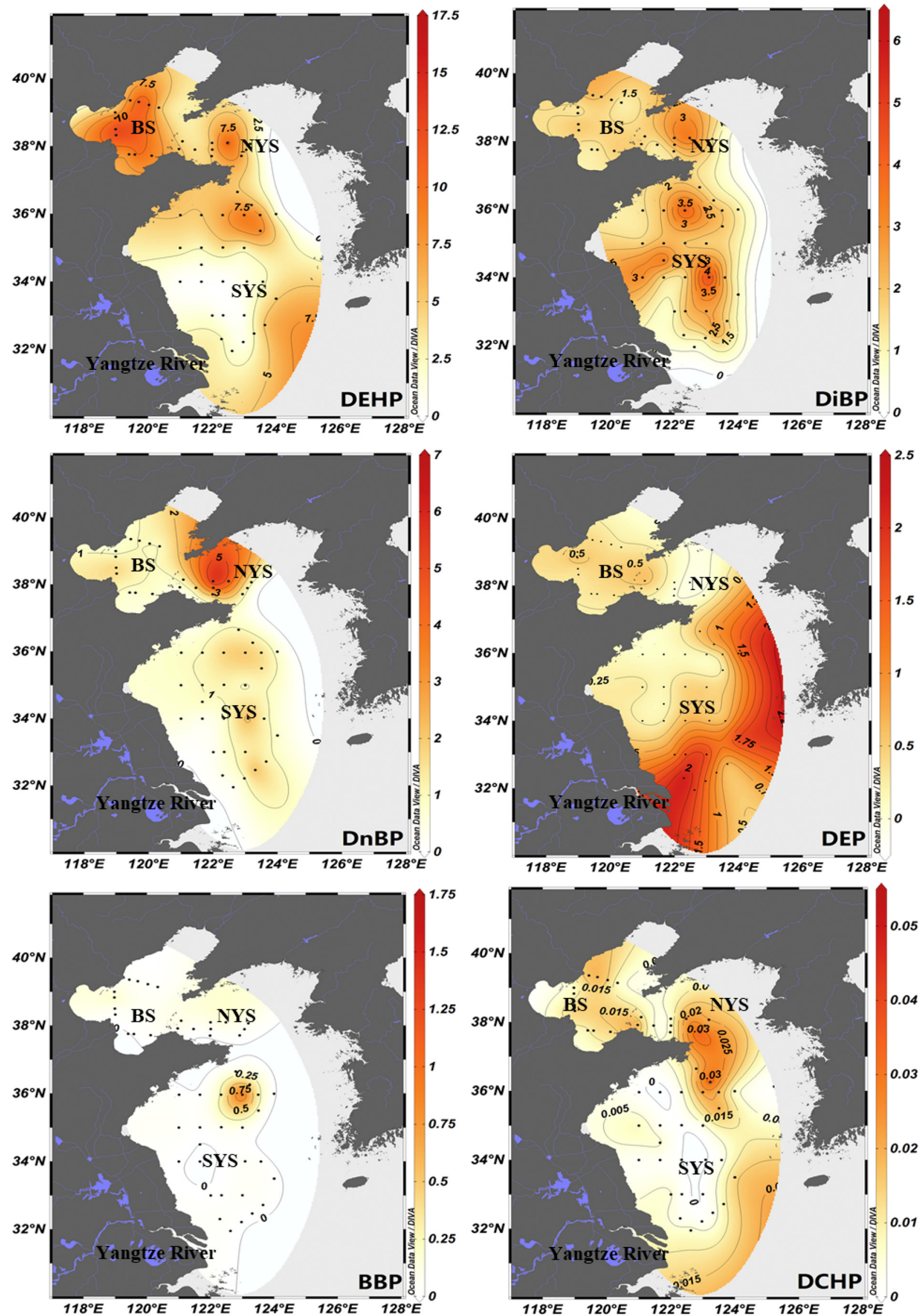

Fig. 2. Distributions of DEP, DiBP, DnBP, BBP, DCHP and DEHP (ng/g) in sediment of the Bohai and Yellow seas 
Table 2

Comparison of PEs concentrations (ng/g) in this study with those measured in global estuaries and coastal seas.

\begin{tabular}{|c|c|c|c|c|c|c|c|}
\hline Location & DEP & DiBP & DnBP & BBP & DCHP & DEHP & Reference \\
\hline Bohai Sea & N.D.-1.12 & $0.77-2.54$ & $1.00-2.24$ & N.D. -0.43 & N.D.-0.02 & N.D.-15.92 & This work \\
\hline Yellow Sea & N.D. -2.50 & $0.22-6.40$ & N.D.-6.79 & N.D. -1.55 & N.D.- 0.55 & N.D. -15.60 & This work \\
\hline Bohai Sea & $10-90$ & $200-6430$ & $300-8850$ & N.D.-150 & N.D.-10 & $330-3680$ & (Zhang et al., 2018c) \\
\hline Yellow Sea & $20-220$ & $290-2540$ & $630-8040$ & $40-90$ & N.D. & $420-1230$ & \\
\hline East China Sea & $49.4-355.0$ & & $55.6-4349.5$ & & & & (Yang et al., 2016) \\
\hline Coastal zone of Qingdao & N.D. & & ND-2744.35 & N.D. & & N.D.-3209.83 & (Zhang et al., 2016) \\
\hline Laizhou Bay & & & $2.00-43.89$ & & & $4.37-4389.24$ & (Xiao et al., 2010) \\
\hline Yellow River & $1.60-7.70$ & & $18,120-34,080$ & & & $9290-50,690$ & (Sha et al., 2007) \\
\hline HaiHe River & & & $120-590$ & & & $310-2730$ & (Chi, 2009) \\
\hline Changjiang River Estuary & N.D.-1130 & N.D.-7980 & N.D. -7080 & & & N.D. -8550 & (Zhang et al., 2018b) \\
\hline Changjiang River Estuary & N.D.-0.18 & $0.02-8.04$ & $0.01-22.0$ & & & N.D. -4.55 & (Zhang et al., 2017) \\
\hline Changjiang River, Chongqing & $15.4-34.2$ & & $557.4-1021.9$ & N.D. & & $729.2-1545.8$ & (Du et al., 2013) \\
\hline Qiantang River & 18 & 170 & 113 & 1.8 & 1.4 & 1555 & (Sun et al., 2013) \\
\hline Chaohu Lake & 15 & 601 & 790 & 33 & 0.3 & 299 & (Kang et al., 2016) \\
\hline Quanzhou Bay & 0.87 & 113.46 & 49.5 & & & 299.83 & (Zhuang et al., 2011) \\
\hline Kaohsiung Harbor, Taiwan & $9.3-33.7$ & $21.9-69.5$ & $37.3-259$ & N.D & & $574-21,559$ & (Chen et al., 2017) \\
\hline Pearl River Delta, Guangzhou & $28-1050$ & $970-71,200$ & $82-1260$ & N.D-280 & N.D-220 & $210-14,160$ & (Zeng et al., 2008) \\
\hline Jiulong River, Southeast China & N.D.-5.8 & $10.2-116.8$ & $1.6-92.8$ & & & $4.3-394.7$ & (Li et al., 2017) \\
\hline Maowei Sea Littoral, Guangxi & & 0.013 & 0.0073 & 0.012 & & 0.064 & (Liao et al., 2015) \\
\hline Kaveri River, India & 16.5 & & 35.5 & 2.6 & & 278 & (Selvaraj et al., 2015) \\
\hline Freshwater Systems of Venda & $160-320$ & & $190-6500$ & & & $20-1120$ & (Fatoki et al., 2009) \\
\hline Ogun river catchments, Nigeria & $80-350$ & & $190-1420$ & & & $20-820$ & (Adeniyi et al., 2011) \\
\hline Anzali wetlands, Caspian Sea (Iran) & & & $120-19,020$ & & & $250-43,120$ & (Hassanzadeh et al., 2014) \\
\hline
\end{tabular}

no significant correlations between the PE concentrations and TIC contents $(p>0.05)$.

The correlations between TOC and individual PEs are shown in Table S3 and Fig. S2. Significant positive correlations were observed between TOC and the concentrations of DiBP $(r=0.44, p=0.001)$, DnBP $(r=0.60, p<0.001)$, BBP $(r=0.52, p<0.001)$, and DEHP $(r=0.37, p=$ 0.01 ), suggesting that TOC can be a factor affect the spatial distribution of major PEs. However, DCHP showed no significant correlation with TOC, which could be caused by its low concentration levels in the sediments. Relatively weak correlation was presented between DEP concentrations and TOC. This may be attributed to the high solubility and low Kow value of DEP, which allows DEP can travel long distances with the oceanic current.

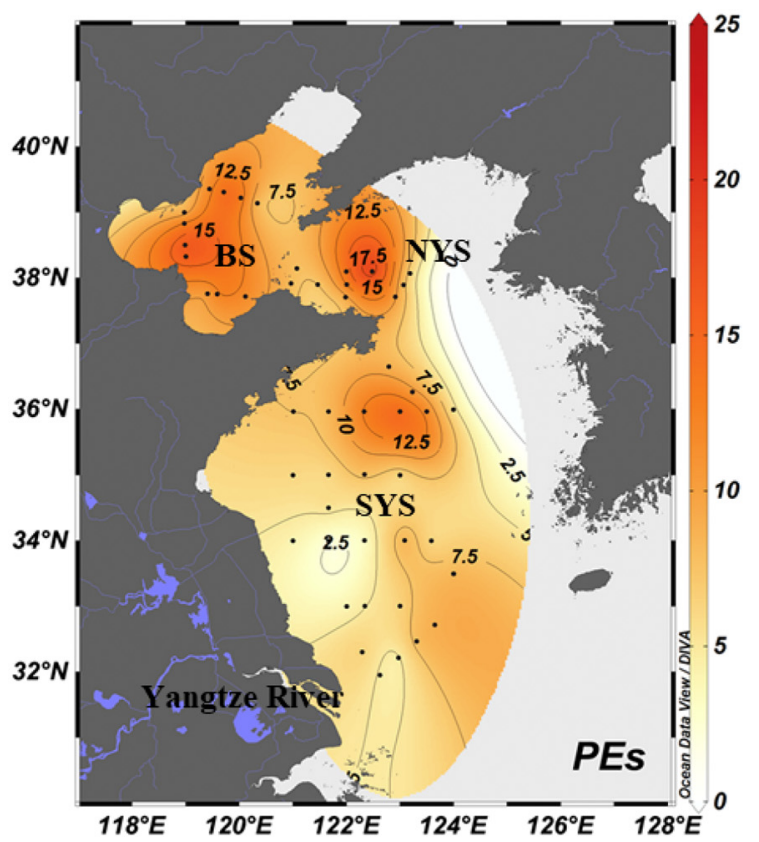

\subsection{Source identification of PEs}

The PE concentrations in the Bohai and Yellow seas are generally 1-3 orders of magnitude lower than those determined in adjacent rivers and coastal areas, highlighting riverine catchments as an important source for the input of PEs in the Bohai and Yellow seas. Among the PE components, DiBP, DnBP, BBP, DCEP, and DEHP showed a significant coefficient among each other (Table S4), suggesting similar discharge sources and transport behavior. However, there was no significant correlation observed between DEP and the other five PEs in this study. According to information collected from the Anon (2014), the industries producing DEP are mainly situated in Hubei, Jiangsu, and Shanghai along the Yangtze River. PE emissions via the Yangtze River estuary can be transported

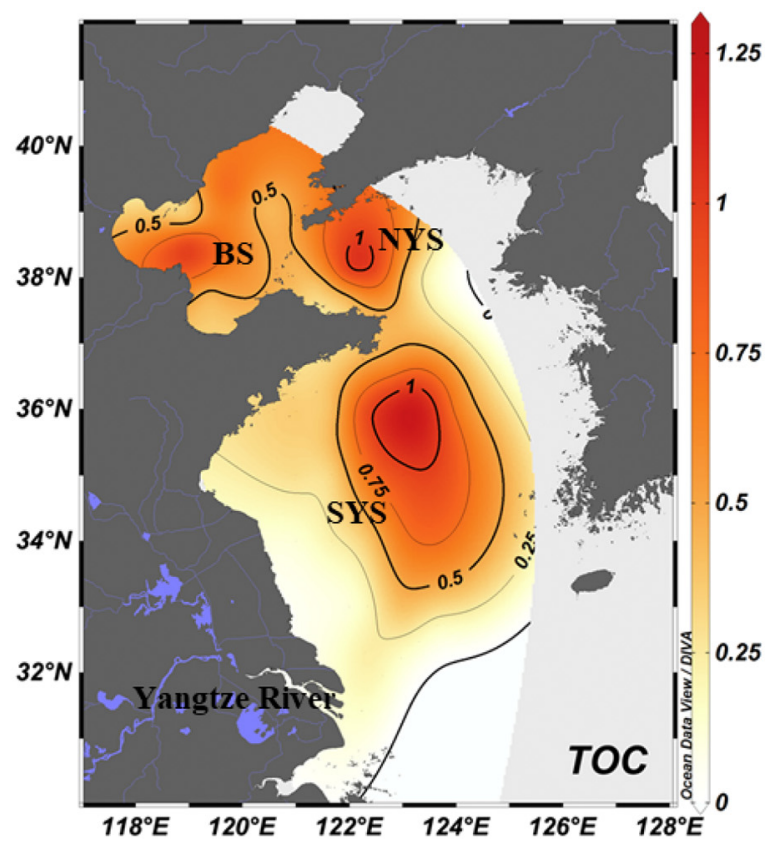

Fig. 3. Distribution of PEs comparable to that of TOC in sediment of Bohai and Yellow seas. 


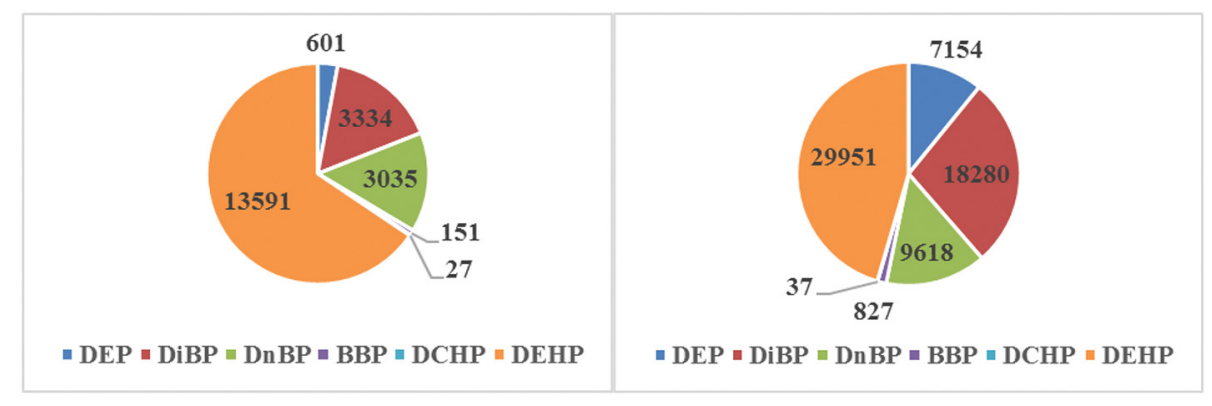

Fig. 4. Inventory of PEs (ton) in sediment of Bohai (left) and Yellow (right) seas.

to the East China Sea and then move northward to the Southern Yellow Sea via the Taiwan Warm Current (Liu et al., 2004, Qiao et al., 2017).

Moreover, atmospheric transport and deposition is also an important source for organic contaminants in a marine environment (Xie et al., 2005). Recently, PEs have been found in PM2.5 and PM10 in the ambient air of Tianjin, Beijing, and Shanghai (Chen et al., 2018; Ma et al., 2014; Zhu et al., 2016). DnBP and DEHP are major components in atmospheric particles as well. The trade winds from the continent may steadily transport atmospheric particles to the Bohai and Yellow seas. Atmospheric deposition of particulate matter including organic carbon and black carbon into the Bohai and Yellow seas has been recently investigated (Fang et al., 2018). The area-integrated atmospheric particulate organic carbon (POC) and particulate black carbon (PBC) depositional fluxes to the Bohai Sea were $355 \pm 8$ and $68 \pm 22 \mathrm{Gg} /$ year, respectively, which accounts for nearly $50 \%$ of the input from riverine systems during 2013 (POC, 781.9, PBC, 150.4 Gg/year). Therefore, particle-bound PEs can be a significant input source for PEs in the sediments of the Bohai and Yellow seas.

Apart from long-range transport through riverine systems and the atmosphere, marine traffic, fishing boats, and mariculture can be direct sources of PEs in marine sediments (Akhbarizadeh et al., 2017; Fries et al., 2013). PEs containing solid waste generated from ship and fishing boats might be directly disposed into the sea. Microplastics have become a severe pollution issue in the Bohai and Yellow seas and which carry many chemical contaminants to the environment (Mai et al., 2018; Zhao et al., 2018). PEs, e.g., DEHP and DnBP, have been identified as major contaminants in microplastic samples collected along the coastal beach of the Bohai Sea (Zhang et al., 2018a). Once microplastics sink to the ocean floor, they can directly release organic contaminants, e.g., PEs, into the surrounding sediments (Bakir et al., 2016). Moreover, marine dumping sites for solid waste may form specific local sources for organic contaminants, e.g., PEs in the sea can spread on the ocean floor following oceanic currents. Although Chinese governments and authorities have also strengthened the protection of the marine environment, the overall situation of China's coastal water pollution remains a great challenge.

\subsection{Inventory of PEs in the marine sediments}

The inventories of PEs in the sediments for the Bohai and Yellow seas were calculated using the following equation (Zhao et al., 2011):

Inventory $=C \times \rho \times A \times D \times a$

where $C(\mathrm{ng} / \mathrm{g})$ is the mean concentration of PEs in the sediment in this work and $\rho\left(\mathrm{g} / \mathrm{cm}^{3}\right)$ is the dry density of the sediment. A $\left(\mathrm{cm}^{2}\right)$ represents the area of the sea, $D(\mathrm{~cm} / \mathrm{y})$ is the sedimentation rate, and a (y) is the number of years considered in the inventory. In this work, the sedimentation rate and the dry bulk density of the Bohai and Yellow seas was estimated as $0.5 \mathrm{~cm} / \mathrm{y}$ and $0.95 \mathrm{~g} / \mathrm{cm}^{3}$, respectively (Qiao et al., 2017). Based on their total areas of $78,000 \mathrm{~km}^{2}$ and $380,000 \mathrm{~km}^{2}$, and five-year accumulation, it was estimated that the inventories of the $\sum 6 \mathrm{PEs}$ are 20.73 and 65.87 tons for the Bohai and Yellow seas, respectively. The uncertainties in the calculation of the inventories were propagated from analytical errors of $C$ and the uncertainty in $\rho$, and $D$ values. An analytical error was estimated to be $20 \%$ for C. The assumption of $\rho$ of $0.95 \mathrm{~g} / \mathrm{cm}^{3}$ and D value of $0.5 \mathrm{~cm} / \mathrm{y}$ may contain an error of $20 \%$ and $50 \%$ for the mud areas of the Bohai and Yellow seas (Qiao et al., 2017). Therefore, a propagated uncertainty was $\sim 57 \%$ for the estimated inventories.

The inventories of the individual PEs in the Bohai and Yellow seas are shown in Fig. 4. The total inventory of DEHP was 43.54 tons, following by 21.61 tons of DiBP, 12.65 tons of DnBP and 7.76 tons of DEP. BBP and DCHP accumulation was $<1$ ton in the Bohai and Yellow seas. The inventories of other organic contaminants have been estimated in the Bohai and/or Yellow seas. A total of 11-19 t of BDE-209 and 1.3-1.9 t of seven PBDEs (Pan et al., 2010) were inventoried in the Bohai Sea, and 0.4-26 t of eight organophosphate esters (OPEs) in the Bohai and Yellow seas (Zhong et al., 2018). Consequently, the inventories of the total PEs are comparable to those for BDE-209, and 10 times higher than those for PBDEs and OPEs.

\section{Conclusion}

This study focused on the concentrations, distributions, and source identifications of PEs in sediments of the Bohai and Yellow seas. High concentrations of PEs were detected with DEHP being the predominant compound in both the Bohai and Yellow seas. A positive correlation between TOC and PEs in the whole region implied a common source of TOC and organic pollutants. Riverine input and transport and deposition with suspended particles in mud areas might be the main factors that influence the distribution patterns of the PEs in the marine sediments while atmospheric deposition could be another notable input source of particle-bound PEs. Given that DEHP, DiBP, and DnBP are more persistent and bioaccumulative, more studies to investigate their level in marine organisms and the transformational products in biota are needed. As it is a great challenge to determine trace concentrations of PEs in marine sediments, more measurements are required to provide appropriate data for assessment of the environmental risk of PEs in marine environments.

\section{Acknowledgement}

This study was financially supported by the Chinese Academy of Sciences (KZCX2-EW-QN210, KZZD-EW-14, and YZ201161), the National Natural Science Foundation of China (40933048 and 41073064) and German BMBF (03F0786C). We are grateful for the field assistance from the crew of Research Vessel Dongfanghong 2 of the Ocean University of China.

\section{Appendix A. Supplementary data}

Supplementary data to this article can be found online at https://doi. org/10.1016/j.scitotenv.2018.10.438. 


\section{References}

Adeniyi, A.A., Okedeyi, O.O., Yusuf, K.A., 2011. Flame ionization gas chromatographic determination of phthalate esters in water, surface sediments and fish species in the Ogun river catchments, Ketu, Lagos, Nigeria. Environ. Monit. Assess. 172, 561-569.

Ajdari, B., Nassiri, M., Zahedi, M.M., Ziyaadini, M., 2018. Determination of phthalate esters in seawater of Chabahar Bay using dispersive liquid-liquid microextraction coupled with GC-FID. Water Sci. Technol. 77, 1782-1790.

Akhbarizadeh, R., Moore, F., Keshavarzi, B., Moeinpour, A., 2017. Microplastics and potentially toxic elements in coastal sediments of Iran's main oil terminal (Khark Island). Environ. Pollut. 220, 720-731.

Anon, 2014. China Plastics Industry Yearbook (Chinese Edition). ZHONG GUO SU LIAO JIA GONG GONG YE XIE HUI.

Bakir, A., O'Connor, I.A., Rowland, S.J., Hendriks, A.J., Thompson, R.C., 2016. Relative importance of microplastics as a pathway for the transfer of hydrophobic organic chemicals to marine life. Environ. Pollut. 219, 56-65.

Chen, C.T.A., 2009. Chemical and physical fronts in the Bohai, Yellow and East China seas. J. Mar. Syst. 78, 394-410

Chen, X.M., An, H., Ao, L., Sun, L., Liu, W.B., Zhou, Z.Y., Wang, Y., Gao, J., 2011. The combined toxicity of dibutyl phthalate and benzo(a)pyrene on the reproductive system of male Sprague Dawley rats in vivo. J. Hazard. Mater. 186, 835-841.

Chen, C.W., Chen, C.F., Dong, C.D., 2013. Distribution of phthalate esters in sediments of Kaohsiung Harbor, Taiwan. Soil Sediment Contam. 22, 119-131.

Chen, W.L., Xie, Z., Wolschke, H., Gandrass, J., Kotke, D., Winkelmann, M., Ebinghaus, R 2016. Quantitative determination of ultra-trace carbazoles in sediments in the coastal environment. Chemosphere 150, 586-595.

Chen, C.F., Chen, C.W., Ju, Y.R., Dong, C.D., 2017. Determination and assessment of phthalate esters content in sediments from Kaohsiung Harbor, Taiwan. Mar. Pollut. Bull. $124,767-774$.

Chen, Y., Lv, D., Li, X.H., Zhu, T.L., 2018. PM2.5-bound phthalates in indoor and outdoor air in Beijing, seasonal distributions and human exposure via inhalation. Environ. Pollut. 241, 369-377.

Chi, J., 2009. Phthalate acid esters in Potamogeton crispus L. from Haihe River, China Chemosphere 77, 48-52

Du, X., Li, X.H., Luo, T.L., Matsuur, N., Kadokami, K., Chen, J.W., 2013. Occurrence and aquatic ecological risk assessment of typical organic pollutants in water of Yangtze River estuary. In: Quan, X. (Ed.), International Symposium on Environ. Sci. Technol. Vol. 18, pp. 882-889.

Fang, Y., Chen, Y.J., Tian, C.G., Wang, X.P., Lin, T., Hu, L.M., Li, J., Zhang, G., Luo, Y., 2018. Cycling and budgets of organic and black carbon in coastal Bohai Sea, China, impacts of natural and anthropogenic perturbations. Glob. Biogeochem. Cycles 32, 971-986.

Fatoki, O.S., Ravandhalala, M.B., Chimuka, L., Genthe, B., Adeniyi, A., 2009. Phthalate este plasticizers in freshwater systems of Venda, South Africa and potential health effects. Water SA 36, 117-125.

Fernandez, M.P., Ikonomou, M.G., Buchanan, I., 2007. An assessment of estrogenic organic contaminants in Canadian wastewaters. Sci. Total Environ. 373, 250-269.

Fries, E., Dekiff, J.H., Willmeyer, J., Nuelle, M.T., Ebert, M., Remy, D., 2013. Identification of polymer types and additives in marine microplastic particles using pyrolysis-GC/MS and scanning electron microscopy. Environ. Sci. Process. Imp. 15, 1949-1956.

Fujii, M., Shinohara, N., Lim, A., Otake, T., Kumagai, K., Yanagisawa, Y., 2003. A study on emission of phthalate esters from plastic materials using a passive flux sampler Atmos. Environ. 37, 5495-5504

Gao, Y., Fu, J., Zeng, L., Li, A., Li, H., Zhu, N., Liu, R., Liu, R., Wang, Y., Jiang, G., 2014. Occurrence and fate of perfluoroalkyl substances in marine sediments from the Chinese Bohai Sea, Yellow Sea, and East China Sea. Environ. Pollut. 194, 60-68.

Hassanzadeh, N., Esmaili Sari, A., Khodabandeh, S., Bahramifar, N., 2014. Occurrence and distribution of two phthalate esters in the sediments of the Anzali wetlands on the coast of the Caspian Sea (Iran). Mar. Pollut. Bull. 89, 128-135.

Hu, L.M., Zhang, G., Zheng, B.H., Qin, Y.W., Lin, T., Guo, Z.G., 2009. Occurrence and distribution of organochlorine pesticides (OCPs) in surface sediments of the Bohai Sea, China. Chemosphere 77, 663-672.

Huang, P.C., Tien, C.J., Sun, Y.M., Hsieh, C.Y., Lee, C.C., 2008. Occurrence of phthalates in sediment and biota, relationship to aquatic factors and the biota-sediment accumulation factor. Chemosphere 73, 539-544.

Jurado, E., Jaward, F.M., Lohmann, R., Jones, K.C., Sima, R., Dachs, J., 2004. Atmospheric dry deposition of persistent organic pollutants to the Atlantic and inferences for the Global Oceans. Environ. Sci. Technol. 38, 5505-5513.

Kang, L., Wang, Q.M., He, Q.S., He, W., Liu, W.X., Kong, X.Z., Yang, B., Yang, C., Jiang, Y.J., Xu, F.L., 2016. Current status and historical variations of phthalate ester (PAE) contamination in the sediments from a large Chinese lake (Lake Chaohu). Environ. Sci. Pollut Res. 23, 10393-10405

Kastner, J., Cooper, D.G., Maric, M., Dodd, P., Yargeau, V., 2012. Aqueous leaching of di-2-ethylhexyl phthalate and "green" plasticizers from poly(vinyl chloride). Sci. Total Environ. 432, 357-364.

Klamer, H.J.C., Leonards, P.E.G., Lamoree, M.H., Villerius, L.A., Åkerman, J.E., Bakker, J.F. 2005. A chemical and toxicological profile of Dutch North Sea surface sediments. Chemosphere 58, 1579-1587.

Li, R., Liang, J., Duan, H., Gong, Z., 2017. Spatial distribution and seasonal variation of phthalate esters in the Jiulong River estuary, Southeast China. Mar. Pollut. Bull. 122, $38-46$.

Li, Q., Zhang, Y., Lu, Y., Wang, P., Suriyanarayanan, S., Meng, J., et al., 2018. Risk ranking of environmental contaminants in Xiaoqing River, a heavily polluted river along urbanizing Bohai Rim. Chemosphere 204, 28-35.

Liao, R., Xv, Y., Zhong, Q., Xv, S., 2015. Distribution and chemical composition of phthalic acid esters in surface sediments in Guangxi Maowei Sea Littoral. J. Ecol. Environ. Sci. $24,1342-1347$.
Liu, S.M., Zhang, J., Li, D.J., 2004. Phosphorus cycling in sediments of the Bohai and Yellow seas. Estuar. Coast. Shelf Sci. 59, 209-218.

Liu, Y., Chen, Z.L., Shen, J.M., 2013. Occurrence and removal characteristics of phthalate esters from typical water sources in Northeast China. J. Anal. Methods Chem. 419349.

Ma, J., Chen, L.L., Guo, Y., Wu, Q., Yang, M., Wu, M.H., Kannan, K., 2014. Phthalate diesters in Airborne PM2.5 and PM10 in a suburban area of Shanghai, Seasonal distribution and risk assessment. Sci. Total Environ. 497, 467-474.

Mai, L., Bao, L.J., Shi, L., Liu, L.Y., Zeng, E.Y., 2018. Polycyclic aromatic hydrocarbons affiliated with microplastics in surface waters of Bohai and Huanghai Seas, China. Environ. Pollut. 241, 834-840.

Meng, J., Hong, S.J., Wang, T.Y., Li, Q.F., Yoon, S.J., Lv, Y.L., Giesy, J.P., Khim, J.S., 2017. Traditional and new POPs in environments along the Bohai and Yellow seas: an overview of China and South Korea. Chemosphere 169, 503-515.

Paluselli, A., Aminot, Y., Galgani, F., Net, S., Sempere, R., 2018a. Occurrence of phthalate acid esters (PAEs) in the northwestern Mediterranean Sea and the Rhone River. Prog. Oceanogr. 163, 221-231.

Paluselli, A., Fauvelle, V., Schmidt, N., Galgani, F., Net, S., Sempere, R., 2018b. Distribution of phthalates in Marseille Bay (NW Mediterranean Sea). Sci. Total Environ. 621, $578-587$.

Pan, X.H., Tang, J.H., Li, J., Guo, Z.G., Zhang, G., 2010. Levels and distributions of PBDEs and PCBs in sediments of the Bohai Sea, North China. J. Environ. Monit. 12, 1234-1241.

Peijnenburg. W., Struijs, J., 2006. Occurrence of phthalate esters in the environment of the Netherlands. Ecotoxicol. Environ. Saf. 63, 204-215.

Qiao, S., Shi, X., Wang, G., Zhou, L., Hu, B., Hu, L., Yang, G., Liu, Y., Yao, Z., Liu, S., 2017. Sediment accumulation and budget in the Bohai Sea, Yellow Sea and East China Sea. Mar. Geol. 390, 270-281.

Schlitzer, R., 2018. Ocean Data View, odv.awi.de.

Schwarzenbach, R.P., Gschwend, P.M., Imboden, D.M., 2002. Environmental Organic Chemistry. 2nd edition. John Wiley \& Sons, New York.

Selvaraj, K.K., Sundaramoorthy, G., Ravichandran, P.K., Girijan, G.K., Sampath, S., Ramaswamy, B.R., 2015. Phthalate esters in water and sediments of the Kaveri River, India, environmental levels and ecotoxicological evaluations. Environ. Geochem. Health 37, 83-96.

Sha, Y.J., Xia, X.H., Yang, Z.F., Huang, G.H., 2007. Distribution of PAEs in the middle and lower reaches of the Yellow River, China. Environ. Monit. Assess. 124, 277-287.

Shi, X., 2014. China Coastal Seas-Marine Sediment. China Ocean Press, Beijing.

Staples, A., Adams, W.J., Parkerton, T.F., Gorsuch, J.W., Biddinger, G.R., Reinert, K.H., 1997a. Aquatic toxicity of eighteen phthalate esters. Environ. Toxicol. Chem. 16, 875-891.

Staples, C.A., Peterson, D.R., Parkerton, T.F., Adams, W.J., 1997b. The environmental fate of phthalate esters: a literature review. Chemosphere 35, 667-749.

Stewart, M., Olsen, G., Hickey, C.W., Ferreira, B., Jelic, A., Petrovic, M., Barcelo, D., 2014. A survey of emerging contaminants in the estuarine receiving environment around Auckland, New Zealand. Sci. Total Environ. 468, 202-210.

Stoppa, F., Schiazza, M., Pellegrini, J., Ambrosio, F.A., Rosatelli, G., D'Orsogna, M.R., 2017. Phthalates, heavy metals and PAHs in an overpopulated coastal region, inferences from Abruzzo, central Italy. Mar. Pollut. Bull. 125, 501-512.

Su, J., Yuan, Y., 2005. Hydrology in China Coastal Sea. Ocean Press, Beijing.

Sun, J.Q., Huang, J., Zhang, A.P., Liu, W.P., Cheng, W.W., 2013. Occurrence of phthalate esters in sediments in Qiantang River, China and inference with urbanization and river flow regime. J. Hazard. Mater. 248, 142-149.

Wang, J., Bo, L.J., Li, L.N., Wang, D.J., Chen, G.C., Christie, P., Teng, Y., 2014. Occurrence of phthalate esters in river sediments in areas with different land use patterns. Sci. Total Environ. 500, 113-119.

Wang, A.M., Wang, H.J., Bi, N.S., Wu, X., 2016. Sediment transport and dispersal pattern from the Bohai Sea to the Yellow Sea. J. Coast. Res. SI 74, 104-116.

Weir, S.M., Wooten, K.J., Smith, P.N., Salice, C.J., 2014. Phthalate ester leachates in aquatic mesocosms: implications for ecotoxicity studies of endocrine disrupting compounds. Chemosphere 103, 44-50.

Xiao, X.T., Ma, Q.M., Cheng, H.O., 2010. Distribution of BDP and DEHP in superficial sediment of Laizhou Bay. Mar. Environ. Sci. 29, 337-341.

Xie, Z., Ebinghaus, R., Temme, C., Caba, A., Ruck, W., 2005. Atmospheric concentrations and air-sea exchanges of phthalates in the North Sea (German Bight). Atmos. Environ. 39, 3209-3219.

Xie, Z., Ebinghaus, R., Temme, C., Lohmann, R., Caba, A., Ruck, W., 2007. Occurrence and air-sea exchange of phthalates in the Arctic. Environ. Sci. Technol. 41, 4555-4560.

Xu, H., Shao, X., Zhang, Z., Zou, Y., Chen, Y., Han, S., Wang, S., Wu, X., Yang, L., Chen, Z., 2013. Effects of Di-n-butyl phthalate and diethyl phthalate on acetylcholinesterase activity and neurotoxicity related gene expression in embryonic zebrafish. Bull. Environ. Contam. Toxicol. 91, 635-639.

Yang, S.Y., Jung, H.S., Lim, D.I., Li, C.X., 2003. A review on the provenance discrimination of sediments in the Yellow Sea. Earth-Sci. Rev. 63, 93-120.

Yang, D., Feng, L., Li, M., Duan, X., Zhang, D., Li, X., 2016. Occurrence and distribution characteristics of phthalic acid esters (PAEs) in surface sediments of the East China Sea. Periodical of Ocean University of China. Vol. 46, pp. 74-81.

Zeng, F., Cui, K.Y., Xie, Z., Liu, M., Li, Y.J., Lin, Y., Zeng, Z., Li, F., 2008. Occurrence of phthalate esters in water and sediment of urban lakes in a subtropical city, Guangzhou, South China. Environ. Int. 34, 372-380.

Zhang D., Liu, N., Zhu, Z., Lu, J., Lin, X., Zhang, Y., Hou, G., Yin, P., 2016. Distribution, chemical composition and ecological risk assessment of phthalic acid esters in surface sediments from typical coastal zones of Qingdao City. Mar. Environ. Sci. 35, 652-657.

Zhang, Z., Zhang, H., Li, J., Yang, G., 2017. Determination of phthalic acid esters in seawater and sediment by solid-phase microextraction and gas chromatography-mass spectrometry. Chin. J. Anal. Chem. 45, 348-355.

Zhang, H., Zhou, Q., Xie, Z., Zhou, Y., Tu, C., Fu, C., Mi, W., Ebinghaus, R., Christie, P., Luo, Y., 2018a. Occurrences of organophosphorus esters and phthalates in the microplastics from the coastal beaches in north China. Sci. Total Environ. 616, 1505-1512. 
Zhang, Z., Zhang, H., Zhang, J., Wang, Q., Yang, G., 2018b. Occurrence, distribution, and ecological risks of phthalate esters in the seawater and sediment of Changjiang River Estuary and its adjacent area. Sci. Total Environ. 619, 93-102.

Zhang, Z., Zhang, H., Zou, Y., Yang, G., 2018c. Distribution and ecotoxicological state of phthalate esters in the sea surface microlayer, seawater and sediment of the Bohai Sea and the Yellow Sea. Environ. Pollut. 240, 235-247.

Zhao, Z., Zhong, G.C., Moller, A., Xie, Z., Sturm, R., Ebinghaus, R., Tang, J.H., Zhang, G., 2011. Levels and distribution of Dechlorane Plus in coastal sediments of the Yellow Sea, North China. Chemosphere 83, 984-990.

Zhao, Z., Tang, J.H., Xie, Z., Chen, Y.J., Pan, X.H., Zhong, G.C., Sturm, R., Zhang, G., Ebinghaus, R., 2013. Perfluoroalkyl acids (PFAAs) in riverine and coastal sediments of Laizhou Bay, North China. Sci. Total Environ. 447, 415-423.

Zhao, J., Ran, W., Teng, J., Liu, Y., Liu, H., Yin, X., Cao, R., Wang, Q., 2018. Microplastic pollution in sediments from the Bohai Sea and the Yellow Sea, China. Sci. Total Environ. 640, 637-645.
Zhong, G.C., Tang, J.H., Xie, Z., Mi, W., Chen, Y.J., Moller, A., Sturm, R., Zhang, G., Ebinghaus, R., 2015. Selected current-use pesticides (CUPs) in coastal and offshore sediments of Bohai and Yellow seas. Environ. Sci. Pollut. Res. 22, 1653-1661.

Zhong, M., Wu, H., Mi, W., Li, F., Ji, C., Ebinghaus, R., Tang, J.H., Xie, Z., 2018. Occurrences and distribution characteristics of organophosphate ester flame retardants and plasticizers in the sediments of the Bohai and Yellow seas, China. Sci. Total Environ. 615, 1305-1311.

Zhu, Z., Ji, Y., Zhang, S., Zhao, J., Zhao, J., 2016. Phthalate Ester concentrations, sources, and risks in the ambient air of Tianjin, China. Aerosol Air Qual. Res. 16, 2294-2301.

Zhuang, W., Yao, W., Wang, X., Huang, D., Gong, Z., 2011. Distribution and chemical composition of phthalate esters in seawater and sediments in Quanzhou Bay, China. Environ. Health 28, 898-902. 